\title{
Erratum
}

\section{Errafum to: Theoretical and Experimental Study of Critical Velocity for Smoke Control in a Tunnel Cross-Passage}

Ying Zhen Li and Bo Lei, Department of HVAC Engineering, School of

Mechanical Engineering, Southwest Jiaotong University, Chengdu 610031

Sichuan, People's Republic of China

Haukur Ingason*, Fire Technology, SP Technical Research Institute of Sweden, Box 857, 50115 Borås, Sweden

\section{Erratum to: Fire Technology, 49, 435-449, 2013 Dol $10.1007 / \mathrm{s} 10694-010-0170-0$}

The error noticed in the first sentence in the Introduction. "the Funicular tunnel fire in Australia" should be corrected to "the Funicular tunnel fire in Austria". 